ARTCIE Identities in transition: living as an asylum seeker

\title{
Anne Douglas
}

Anne Douglas is a consultant clinical psychologist and Head of Trauma Services for NHS Greater Glasgow and Clyde. She is an honorary senior clinical lecturer at the University of Glasgow and has specialised in the field of trauma for over 20 years. In 2000, she set up the Compass mental health liaison team for asylum seekers and refugees. In 2006, she received the British Psychological Society Award for Promoting Equality of Opportunity.

Correspondence Dr Anne Douglas, Compass Team, Unit 35 Hyde Park Business Centre, 60 Mollinsburn Street, Glasgow G21 4SF, UK. Email: anne.douglas@ggc. scot.nhs.uk
†For an outline and discussion of UK immigration legislation in Advances see Bacon L, Bourne R, Oakley C, et al (2010) Immigration policy: implications for mental health services, 16: 124-32. Ed.

\begin{abstract}
SUMMARY
The process of forced immigration is a challenge for a person's sense of identity. The traumatic events that precede flight (e.g. torture or rape) may have an impact on the individual's sense of self. By the time the person arrives in the UK, their sense of identity may also have been affected by the significant loss of their homeland and, often, family members. On arrival, the person is given the 'temporary' label of asylum seeker. Although this status offers many the hope of refuge from persecution, there are significant constraints inherent in this role. Until recently, asylum seekers in the UK could be in limbo for many years as their case was considered. Although more recent legislative changes have attempted to speed up the process it can still be lengthy. This article outlines the multiple threats to an asylum-seeking person's sense of identity and associated mental health problems. Ways in which mental health professionals can support the person's sense of identity during this transition are discussed.

\section{DECLARATION OF INTEREST}

None.
\end{abstract}

The UK Home Office's New Asylum Model (Refugee Council 2007) aims to process people's cases within 6 months, although this can extend with the appeal process. ${ }^{\dagger}$ This article looks at the ways mental health professionals can support an asylum seeker's sense of identity during this stressful transition.

\section{Loss of home}

Asylum seekers and refugees lose their home, their jobs and often their families. The loss of homeland can lead to a profound sense of disorientation. Papadopoulos (2002: pp. 17-18) describes home as 'a mosaic substratum of sounds, smells, taste, language, architectural style which gives people a sense of predictability in their lives'. He continues, 'when this mosaic substratum is disturbed when people lose their homes and become refugees, there is a sense of bewilderment, a sense of unreality and of an inexplicable gap because people lose something they were not aware they had in the first place'. Cultural bereavement (Eisenbruch 1990) is a term used to describe this response.

\section{Separation from family}

Cultures may be broadly separated into independent or interdependent. In independent cultures, such as in the Western world, the individual's sense of autonomy, separateness and independence is supported and encouraged. By contrast, in interdependent cultures, loyalty and a sense of duty to the group are valued. Interdependence and the identity of the group are sanctioned over an individual's personal identity (Green 2005). To lose the group is to lose a fundamental way of being in the world. Part of my work is with the Compass mental health liaison team in Glasgow, which helps asylum seekers and refugees. Patients attending Compass for their initial assessment appointment are sometimes more concerned about missing family members and/or connecting with people from their own community in this country than their post-traumatic symptoms. On trying to find out what kind of help a Somali woman (with a history of significant trauma) sought, one of our clinicians was told 'I am searching for a Somali community to look after me'.

Asylum seekers are also often separated from their families in traumatic circumstances and they may not know if their relatives are alive or dead.

\section{Impact of traumatic events before flight}

Asylum seekers by definition are fleeing persecution in their homeland and are seeking refugee status under the Article 1 of the United Nations' Geneva Convention of 1951:

People who because of a well-founded fear of persecution, for reasons of race, religion, nationality, membership of a particular social group or political opinion, leave their country of origin and are unable or unwilling to avail themselves of the protection of that country.

Asylum seekers have often been attacked precisely because of central features of their identity. The personal meaning given to these traumatic events is influenced by a wide range of factors, including the person's culture and faith. If we take the example of rape, there may be some universal similarities in how women experience the initial impact of rape (e.g. feeling dirty, defiled, damaged). In some cultures, however, a girl's or 
woman's honour is a core construct, and rape is seen as an act which brings irrevocable social shame on the woman. Women attending Compass from cultures as diverse as Somalia and Albania have reported reactions such as 'When you are raped, you are nothing' and 'When you lose the honour, you lose everything'.

During peoples' experiences of being detained, tortured and/or raped there are many events that contribute to a deep sense of shame and personal degradation; for example, being stripped naked or being kept in filthy conditions without a toilet. People may also have been forced to behave in ways that are deeply humiliating. During such attacks, including torture, the hatred and scorn that the perpetrator feels for the victim's ethnic, religious or political group is forcibly communicated to the individual. Many of my patients have said, 'I was treated like an animal' or 'I have lost myself'. For some individuals this is an extreme version of what they had already experienced from the dominant political or ethnic group over a period of time. For others, civil unrest means that a previously enjoyed good standard of life where they were treated with respect is suddenly and violently snatched from them: their world is turned upside down.

\section{Asylum-seeking mothers with babies born as a result of rape}

In war, rape is often used as a militaristic strategy: men go into hiding and the aggressors use rape as a way of inflicting the maximum pain on women and, as a consequence, indirectly on the men. Politically, rape may also be seen as a method of ethnic cleansing.

A woman who conceives as a result of rape is faced with some extremely difficult choices: abortion (if religious beliefs permit and if she arrives in the UK before the 24th week of her pregnancy), giving her baby up for adoption or keeping the child. The mother who decides to keep the baby always fears being reminded of the rape when she looks at her baby. This may be particularly the case if the child is a boy. Complex psychological work is required to discuss issues concerning the identity of the child and whether the mother can find a way of remembering that she is looking at a baby and not the rapist.

\section{Being attacked for political or religious beliefs}

Some patients attending Compass describe being tortured or raped because of their faith or political beliefs. A Kurdish man said 'Being a Kurd was the most important thing in my life and what I fought for, but that was also the reason I was tortured'. A
Muslim woman reported, 'The men who attacked me were Muslims too, how can this be? I don't believe in God anymore'. Such patients have described abandoning or distancing themselves from core aspects of their identity, leaving them feeling empty. There is some research evidence, however, that suggests that strong commitment to a cause may protect against the development of post-traumatic stress disorder (PTSD) in victims of torture (Basoglu 1994).

Asylum seekers' relationships with their home country can also change because of the traumatic events which led them to flee. Some people report straightforward feelings of loss for their country, but for others the relationship can become more ambivalent. Some describe a tension between the love felt for their country and hatred because it is associated with the murder of their family. In extreme cases, the person may refuse to use their first language, as it reminds them of their oppressors, preferring a second language such as English.

\section{New identity of 'asylum seeker'}

To this complex amalgam of loss of country, culture, family (e.g. through murder) and potential loss of aspects of the self (e.g. through torture or rape) comes a new threat to identity - the label of asylum seeker. The opportunity to seek and be given sanctuary should not be underestimated; however, subjectively, life as an asylum seeker is defined mainly by what one cannot do. A fixed dispersal policy means that people seeking asylum who need accommodation have no choice over where they stay in the UK. Newly arrived asylum seekers are also not allowed to work for a minimum of 1 year. (Thereafter, the main asylum applicant can apply to the Home Office for permission to work only if the delay in the asylum process has not been the fault of the asylum seeker.) Professional and manual workers alike can find this a restriction which hits at the heart of who they are.

Educational opportunities are permitted and are welcomed, but once again they are restricted to a certain level. Benefit is fixed at $70 \%$ of the basic level of income support. Porter \& Haslam's (2005) meta-analysis demonstrated the important role of post-displacement factors such as institutional and temporary private accommodation and restricted economic opportunities such as no right to work in negatively affecting mental health.

The induction into the identity of the asylum seeker is reminiscent of how Goffman (1961: pp. 25-26) in his classic book Asylums, describes the impact on a person of entering a total institution such as a psychiatric hospital or a prison: 
The inmate, then, finds that certain roles are lost to him by virtue of the barrier that separates him from the outside world. The process of entrance typically brings other kinds of loss and mortification as well... admission procedures, taking a life history, photographing, weighing, fingerprinting, assigning numbers, searching, ... assigning to quarters ... The new arrival is shaped and coded into an object that can be fed into the administrative machinery of the establishment.

\section{Asylum seekers in limbo}

Asylum seekers may be in limbo for many months, even those being managed under the New Asylum Model (Refugee Council 2007). People under the previous legislation may be in this state of uncertainty for years. Patients who are asylum seekers frequently describe this limbo state as similar to being in prison or being tortured. The prolonged stress of not being allowed to take full part in society can steadily erode a person's identity. Frequently people say, 'I am losing myself' or 'I have lost myself'.

As mentioned earlier, for people from collectivist or interdependent societies, identity is usually defined in group terms rather than speaking of an autonomous individual identity. These cultures downplay the independent self in favour of the communal self (Nelson 2004). To be separated from one's family and social group (often in traumatic circumstances) and not be able to fully enter and connect with a new society can be a debilitating experience (Box 1).

Berry (1980) describes a range of ways in which a refugee/immigrant may position themselves in relation to both their own culture and that of the host country. For example, the person might distance themselves from their culture of origin and completely embrace the host culture - this may be termed assimilation. Alternatively, they might respect both what is important from their own culture and their host culture, which would be termed integration. Another position would be to completely hold to the values and customs of the person's own culture and to distance

BOX 1 Case study of an asylum seeker in limbo

John from Africa had been in the asylumseeking process for 7 years when his general practitioner referred him because of his depression. John described his prolonged state as an asylum seeker as follows:

'I love my country, I miss my country, I've lost everybody - how will I start again? How can I live with no mother, father, brothers and sisters? Who will I call? If I die, who will bury me? I can't go back to Africa; the same people who killed my family will kill me. I am losing myself. I used to be able to swim but I've forgotten. I've started college; I am supposed to be happy, but in my condition, a good thing is like a bad thing.

(Published with John's permission)

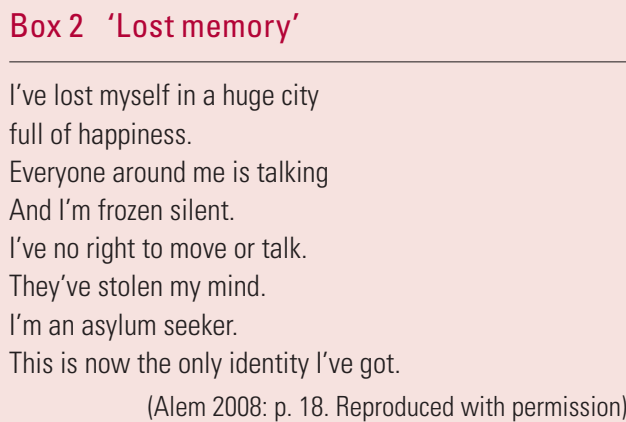

themselves from the behaviour and traditions of the host country; this may be termed separation or segregation. For asylum seekers it can be impossible to know how to position themselves in relation to the host country as they do not know whether they can stay or will have to return. Alem (2008), an asylum seeker from Eritrea, captures some of this disabling feeling in her poem 'Lost memory' (Box 2).

Recent research (Ryan 2008) showed that an uncertain legal status was significantly associated with ongoing severe distress in forced immigrants.

\section{Being granted leave to remain/refugee status}

The long hoped-for status of refugee or having 'indefinite leave to remain' can have its own challenges. The following fictitious example is typical of the patients I see. Amina (45 years old) had chronic depression which had not responded to a range of antidepressant medication. She was surprised that her mood had not lifted even when, after 7 years, she was given indefinite leave to remain. She agreed with me that it was difficult to suddenly start moving forwards when her life had been on hold for so long. It was as if a traffic light stuck on red had finally changed to green but, by that point, she had given up hope.

\section{The pain of survivor guilt}

Moving on with life when an asylum seeker has been given refugee status can also be complex because the person may experience this as betrayal, abandonment of dead relatives or those still missing or in prison. 'I want to die and be with my family' is often heard. Lifton (1983), writing about survivors of Hiroshima, differentiated between 'animating guilt' and 'static guilt'. He said that static guilt keeps the individual bound to the experience and unable to move on, whereas animating guilt drives self-examination and some resolution of the guilt of survival. It may be helpful 
to ask the person who wants to die so that they can be with their family what they think their mother or father would advise them if they were still alive. The patient will usually say that their parent would want them to live, study or work hard, or to search for missing relatives. In time, they may then see that these aims are ways of honouring the memory of their family.

\section{Supporting peoples' identity during the asylum-seeking process}

Mental health problems, including depression and PTSD, are frequent among asylum seekers (McColl 2006). In a previous issue of Advances, McColl et al (2008) suggested some useful ways to help clinicians in their assessment, diagnosis and treatment of asylum-seeking patients. Here, I provide additional focus on the management of issues regarding the person's sense of identity.

\section{Initial mental health assessment interview}

The key word when relating to asylum seekers is respect. This can be communicated in many ways and can be vital in helping the patient begin to rebuild their ravaged sense of identity (Box 3). Respect for the person's culture can initially be communicated through sending the patient an appointment letter in their own language (together with one in English, in case they have to ask a local person the way). Enclosing a map, particularly one with digital photos showing key landmarks near the clinic, makes it is easier for the person to find it unaided. Such maps are easily created using the internet.

Ideally, reception staff should receive some training in how to greet patients who are asylum seekers. Contact with officialdom is usually an unpleasant and stressful process for this group of people. To be welcomed with a smile and to be shown a seat requires no words but a little thought.

\section{Using interpreters}

Consideration should be given to booking an interpreter. To subject a patient to the difficult process of communicating mental distress in limited English is not acceptable and can be experienced by the patient as humiliating. Even patients who have reasonable English may revert to their mother tongue when distressed and disturbed. Members of the family should not be used to interpret as this can mean that the person is not free to disclose their history. As a rule, female interpreters should be booked for female patients. If a man has been subjected to torture, which will often include sexual torture, he may also prefer a
BOX 3 Supporting an asylum seeker's sense of identity

- Ensure that the patient is sent an appointment letter in their own language. An interactive appointment card can easily be created on Harpweb Communicate (www.communicatehealth.org.uk/card)

- Useful tips to aid the first session can be found on the Compass website (www.nhsggc.org uk/compass) or on the Harpweb website (www.mentalhealth.harpweb.org.uk)

- Create a map of your clinic/hospital which includes a digital photo of your building and shows the main entrance

- Check that the patient's name has been spelled correctly

- Ask how they would like to be addressed

- Ask about their previous occupation and education

- Discuss previous and current leisure interests

- Sensitively ask about their family of origin, partners and children

- Note down the names of missing family members, including children

- Ask if they have a faith and if it is important to them

female interpreter as this may be experienced as less shaming.

Ethnic differences should also be thought about; for example, if the clinician is seeing a patient from Chechnya, it would be preferable to ask for a British interpreter who speaks Russian than to arrange for a native Russian to attend. Basic background information on the country can be obtained on the internet (Box 4).

When the interpreter arrives, and before the interview properly begins, the patient should be asked if they are comfortable with the interpreter. If they are not, the appointment should be rescheduled with a more appropriate interpreter.

\section{Checking personal details}

It is important to check the person's name, whether it has been spelled correctly on the referral letter and how they would like to be addressed. This all forms part of a process of communicating that they are important. Where mistakes have been made by the original referrer or their secretarial staff,

\section{BOX 4 Preparing for a culturally sensitive interview with an asylum seeker}

Carry out some background reading on the patient's country before you see them. The following websites are useful:

- Home Office country of origin information service (www.homeoffice.gov.uk/rds/country_reports.html) the Human Rights section is particularly helpful

- BBC country profiles (http://news.bbc.co.uk/1/hi/ country_ profiles/default.stm)

- Amnesty International (www.amnesty.org) 
these can be changed in the case notes in front of the patient and an apology given. For example, a female patient from Africa was distressed to find out that her religion had been noted as Christian when she was Muslim. A man from Iran was shocked to find out that his referral letter said that he was from Iraq.

\section{Reassurance}

Time needs to be spent explaining the purpose of the interview. In many countries, having mental health problems carries an immense stigma and patients may need reassurance that the interview is confidential and that the interpreter is also bound by a code of conduct.

\section{Family history}

Often the most pressing concern for people is the separation from or loss of their families. Taking a routine family history can stir up painful memories. This may be sensitively asked as 'Do you have any family left at home?' This allows the patient to start with the living or missing members of their family before moving on to the more painful subject of those who have been killed.

\section{Religious beliefs}

Many but not all asylum-seeking patients will have a religious belief which it may be helpful to explore, as it may form an important part of both their identity and their coping strategies. ${ }^{*}$ At an assessment interview this can be asked about in an open and thoughtful manner bearing in mind that people may have been persecuted as a result of their faith. It is also vital not to hold preconceptions, for example because someone comes from a predominantly Christian country they are bound to be Christian. One can ask, 'Do you have a faith?', and if the answer is affirmative follow with 'Is your faith important to you?' and 'Do you go to a place of worship?' In this way, the patient can disclose the importance or otherwise of religious faith in their life.

\section{Engaging with the person}

It is essential to ask the person which stage they are at in the asylum-seeking process. The clinician should add that the reason for asking is to understand the pressures the person is facing at the moment. It can also inform decisions about treatment. One would not wish to start trauma processing therapy if someone has been refused asylum and may shortly be returned to the country of the original conflict.

The clinician can often do best by listening to the patient's account of what troubles them and resisting the temptation to reduce all their problems to a formulation that focuses on the sequelae of traumatic events. It is helpful to ask the person about their occupation, studies or daily routine in their home country. The opportunity to talk about aspects of identity prior to the events that caused them to flee can help the person re-connect with lost aspects of the self.

Members of the mental health team who see patients at their home can also support their social role by accepting basic hospitality such as tea or coffee. On a home visit I was offered tea in a china cup placed on a small gold doily. When I remarked on how pretty this was, the woman replied, 'I like to pretend I am keeping house the way I used to.'

\section{Supporting the person's identity through social networks, education and work}

\section{Social networks}

Patients who wish to connect with others from their ethnic group may be given the numbers of local groups or put in touch with the Refugee Council (www.refugeecouncil.org.uk), which can signpost them. It should not be automatically assumed that everyone will wish this, as in times of civil war people can be most suspicious of those from their own country.

Those who have lost touch with families during a time of conflict and who wish to try and find them can be put in touch with the British Red Cross (www.redcross.org.uk), who have a family tracing system. Not everyone will wish to pursue this, preferring not knowing to finding out the worst.

\section{Group programmes}

Group programmes using activities such as arts and crafts can reduce feelings of isolation, establish a sense of safety and go some way to restoring the person's self-esteem. Asylum seekers may join activity groups run by occupational therapists and/or community psychiatric nurses. In Compass, a 10-week women's group led by the art therapist has been a much valued and heavily used component of therapy over the past 6 years. A Somali woman described how the group helped her: 'Somalia gone, home gone, family gone. Group is now father and mother. Here we play, laugh, have fun... just like home'. Men have benefited from the social interaction and work provided by a gardening project in the hospital grounds. A Turkish man volunteered, 'You have worms in Scotland, just like in my country!' Most recently, our child and adolescent psychologist ran a group for unaccompanied children and young people, which was much appreciated by the young people. 
The Compass user group has provided a forum for patients to be involved in service evaluation and design, but has also been spontaneously used as a place to discuss the impact of the asylum process on mental health. Group members have been supported in finding a way to represent their concerns at a more strategic level, which has been an empowering experience for them.

\section{Education and work}

All asylum seekers are allowed to go to school or college. This opportunity is often used to learn English. Where courses are full, local groups such as ESOL (English for speakers of other languages) can often help.

Although asylum seekers are not allowed to undertake paid work, they can find out about voluntary work at their local volunteer centres. This can benefit both themselves and the local community. In traditional communities, work outside the home is central to the identity of men. For example, a male patient said that being prevented from working made him feel like he was a woman. Another man said that he felt like a baby having to learn everything again. Getting involved in appropriate voluntary work can quickly restore such a person's sense of work identity.

The General Teaching Council of Scotland allows those who are teachers to complete the process of registration while they are asylum seekers. If they are granted refugee status they can then immediately seek employment. Similar work-related schemes exist for asylum-seeking health professionals.

\section{Treatment}

Asylum seekers embarking on therapy for traumarelated problems will thus benefit from a holistic package of care which touches on all areas of their identity. This is similar to a traditional rehabilitation programme, seeking to restore a person's optimum level of functioning. Physiotherapy, pain clinics and other medical or surgical interventions may also be required. A wide range of translated materials is available to patients, covering all aspects of physical and mental health (Box 5).

BOX 5 Translated mental health information

- Multikulti (www.multikulti.org.uk)

- Royal College of Psychiatrists (www.rcpsych.ac.uk/ mentalhealthinfoforall/translations.aspx)

- Mind (www.mind.org.uk/help/foreign_language_ resources)
Trauma-focused therapy and/or drug regimes must be complemented by social, educational and vocational opportunities which should be gender, culture and age appropriate. Psychological therapies will also focus on the person's sense of self and how it has been changed by displacement, bereavements, trauma and the asylum-seeking process. Unaccompanied children and young people will need specific guidance as they grow up in a new and unfamiliar land without the guidance of their parents. Social workers can provide invaluable practical and emotional support to these children.

\section{Conclusions}

Life as an asylum seeker poses immense challenges to a person's sense of identity. The person is trapped in limbo, which may be exhausting, depressing and in which they can feel powerless. This adds to previous losses of country, family and aspects of themselves through traumatic experiences. A formulation needs to be multifactorial taking a wide range of pre- and post-displacement factors into account. As mental health professionals we can support people's natural resilience and identity through holistic assessments which ask about areas of strength as well as difficulty, interventions which are social, educational and vocational, as well as more formal psychotherapies and drug treatments.

\section{References}

Alem F (2008) Lost memory. In Second Home (ed K O'Rourke). Maryhill Integration Network

Basoglu M, Paker M, Paker O, et al (1994) Psychological effects of torture: a comparison of tortured with nontortured political activists in Turkey. American Journal of Psychiatry 151: 76-81.

Berry JW (1980) Acculturation as varieties of adaptation. In Acculturation: Theory, Models and Some New Findings (ed A Padilla): 9-25. Westview.

Eisenbruch M (1990) The Cultural Bereavement Interview: a new clinical research approach for refugees. Psychiatric Clinics of North America 13: 715-35.

Goffman E (1961) Asylums. Penguin Books.

Green EGT, Deschamps J, Paez D (2005) Variation of individualism and collectivism within and between 20 countries: a typological analysis. Journal of Cross-Cultural Psychology 36: 321-39.

Lifton RJ (1983) Responses of survivors to man-made catastrophes. Bereavement Care 2: 2-6.

McColl H, Johnson S (2006) Characteristics and needs of asylum seekers and refugees in contact with London community mental health teams: a descriptive investigation. Social Psychiatry and Psychiatric Epidemiology 41: 789-95.

McColl H, McKenzie K, Bhui K (2008) Mental healthcare of asylumseekers and refugees. Advances in Psychiatric Treatment 14: 452-9.

Nelson K, Fivush R (2004) The emergence of autobiographical memory: a social cultural developmental theory. Psychological Review 11: 486-511.
MCQ answers

1 b $\quad 2$ c $\quad 3$ c $\quad 4 c \quad 5 d$ 
Papadopoulos RK (2002) Refugees, home and trauma. In Therapeutic Care for Refugees: No Place Like Home (ed RK Papadopoulos): 9-40. Karnac Books.

Porter M, Haslam N (2005) Predisplacment and postdisplacement factors associated with mental health of refugees and internally displaced persons. A meta-analysis. JAMA 294: 602-12.
Refugee Council (2007) The New Asylum Model. Refugee Council (http:// www.refugeecouncil.org.uk/Resources/Refugee\%20Council/downloads/ briefings/Newasylummodel.pdf).

Ryan DA, Benson CA, Dooley BA (2008) Psychological distress and the asylum process: a longitudinal study of forced migrants in Ireland. Journal of Nervous and Mental Diseases 1: 37-45.

\section{MCQs}

Select the single best option for each question stem

\section{Asylum seekers are:}

a allowed to seek employment on arrival in the UK

b not allowed to work for at least 1 year after arrival

c allowed to apply for work after a year if they were late with their asylum application

$\mathrm{d}$ allowed to claim unemployment benefit

e able to encourage their partners to work.

2 People seeking refugee status under the Geneva Convention on Human Rights 1951:

a can also be called economic migrants

b are called refugees when they arrive in UK

c have a well-founded fear of persecution

$\mathrm{d}$ are health tourists

e need to have spent time in a refugee camp.
3 Psychiatrists should send an asylumseeking patient:

a an appointment letter in English

b an appointment letter in the patient's own language

c an appointment letter in the patient's own language and in English

$\mathrm{d}$ an 'opt-in' to treatment letter requiring the patient to telephone the clinic

e a form to establish whether they need to pay for their treatment.

4 Asylum seekers who distance themselves from their own culture and immerse themselves in the host country's culture may be described as:

a integrated

b segregated

c assimilated d marginalised

e separated.

5 When booking an interpreter, one does not need to consider their:

a gender

b ethnic group

c religion

d age

e previous relationship with the patient. 